\title{
Change in Pericardial Fat Volume and Cardiovascular Risk Factors in a General Population of Japanese Men
}

\author{
Itsuko Miyazawa, MD, PhD; Takayoshi Ohkubo, MD, PhD; Sayaka Kadowaki, MD, PhD; \\ Akira Fujiyoshi, MD, PhD; Takashi Hisamatsu, MD, PhD; Aya Kadota, MD, PhD; \\ Hisatomi Arima, MD, PhD; Matthew Budoff, MD; Kiyoshi Murata, MD, PhD; \\ Katsuyuki Miura, MD, PhD; Hiroshi Maegawa, MD, PhD; \\ Hirotsugu Ueshima, MD, PhD for the SESSA Research Group
}

\begin{abstract}
Background: Pericardial fat volume (PFV), defined as the volume of ectopic fat in and around the heart, is associated with the atherosclerotic process in coronary arteries. The magnitude of change in PFV over time and the factors affecting this change in a general population, however, have not been investigated.
\end{abstract}

Methods and Results: Cardiac computed tomography (CT) was carried out at baseline and at follow-up in 623 Japanese men aged 40-79 years without a history of cardiovascular disease who were selected randomly in Kusatsu (Shiga, Japan). PFV was measured on cardiac CT in a qualified laboratory. Age, heart rate, triglycerides, and obesity measurements (weight, body mass index, and waist circumference) were significantly and positively associated with PFV at baseline. Over an average interval of 4.7 years, median PFV increased significantly from $64.1 \mathrm{~cm}^{3}$ (IQR, $\left.47.2-90.0 \mathrm{~cm}^{3}\right)$ to $73.6 \mathrm{~cm}^{3}$ (IQR, 53.3-98.1 $\left.\mathrm{cm}^{3} ; P<0.001\right)$. Current smoking and heart rate were significantly and independently associated with changes in $P F V(B=3.336, P<0.001$ and $B=6.409, P=0.003$, respectively).

Conclusions: PFV increased significantly over time in a population-based observational study of Japanese men. PFV change was significantly and independently associated with smoking status and heart rate, suggesting that quitting smoking might help reduce PFV, which could be expected to decrease the risk of coronary artery disease.

Key Words: General population; Longitudinal change; Pericardial fat; Smoking

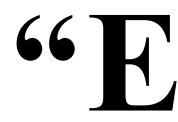
ctopic fat" is defined as excess adipose tissue in locations not classically associated with storage of adipose tissue. ${ }^{1}$ It shares a common embryonic origin with abdominal visceral fat. ${ }^{2,3}$ "Pericardial fat" is ectopic fat in and around the heart. It can function as a lipid-storing depot; as an endocrine organ secreting hormones; and as an inflammatory tissue secreting cytokines and chemokines. ${ }^{2}$ Pericardial fat may have a direct role in the atherosclerotic process in coronary arteries through local release of inflammation-related cytokines. ${ }^{4}$ Pericardial fat volume (PFV) has been shown to be associated with coronary atherosclerosis, ${ }^{3,5-7}$ or the prevalence of coronary artery disease (CAD) ${ }^{\mathbf{4 , 8 9}}$ or cardiovascular disease (CVD) ${ }^{8}$ in patient-based cohort studies ${ }^{3,6-8}$ and population-based cohort studies. ${ }^{4,5,8-10}$ In Japan, PFV has been reported to be associated with the severity of $\mathrm{CAD}^{11,12}$ and

\section{Editorial p 2475}

inflammation of the coronary arteries in CAD patients. ${ }^{13}$ Longitudinal changes in PFV, however, have not been examined in a general population: only one study in the USA, based on the registry of a selected population, has reported longitudinal changes in PFV. ${ }^{14,15}$

The present study examined longitudinal changes in PFV and associations between PFV changes and classical cardiovascular risk factors in a community-based cohort of Japanese men.

\section{Methods}

The aim of the Shiga Epidemiological Study of Subclinical

Received February 1, 2018; revised manuscript received June 5, 2018; accepted June 14, 2018; released online July 26, 2018 Time for primary review: 54 days

Department of Medicine (I.M., H.M.), Department of Public Health (T.O., S.K., A.F., T.H., A.K., H.A., K. Miura, H.U.), Center for Epidemiologic Research in Asia (A.K., K. Miura, H.U.), Department of Radiology (K. Murata), Shiga University of Medical Science, Otsu; Department of Hygiene and Public Health, Teikyo University School of Medicine, Tokyo (T.O.); Department of Environmental Medicine and Public Health, Faculty of Medicine, Shimane University, Izumo (T.H.); Department of Preventive Medicine and Public Health, Faculty of Medicine, Fukuoka University, Fukuoka (H.A.), Japan; and Los Angeles Biomedical Research Institute at Harbor-University of California Los Angeles, Los Angeles, CA (M.B.), USA

Mailing address: Itsuko Miyazawa, MD, PhD, Department of Medicine, Shiga University of Medical Science, Seta Tsukinowa-cho, Otsu 520-2192, Japan. E-mail: shimojo@belle.shiga-med.ac.jp

ISSN-1346-9843 All rights are reserved to the Japanese Circulation Society. For permissions, please e-mail: cj@j-circ.or.jp 


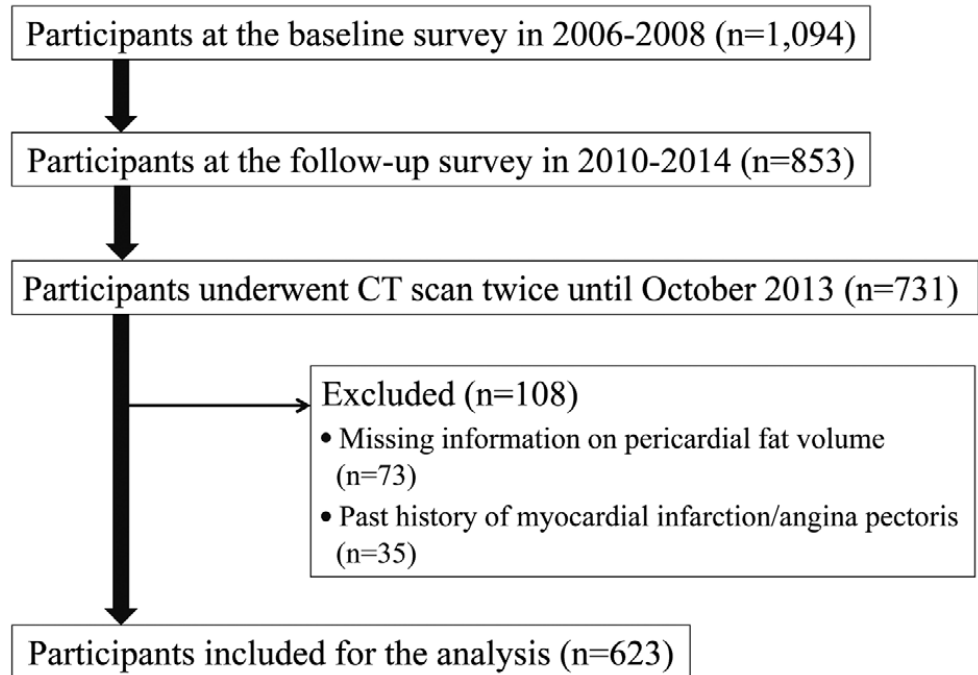

Figure 1. Flowchart of subject selection. CT, computed tomography.
Atherosclerosis is to examine the various factors associated with subclinical atherosclerosis. The design of this study is described elsewhere. ${ }^{16}$ Briefly, 1,094 Japanese men aged 40-79 years were selected randomly from the Residential Basic Book of Kusatsu in Shiga Prefecture in Japan. The participation rate was $46 \%$. Baseline and follow-up studies were performed from 2006 to 2008 and from 2010 to 2014, respectively. Mean follow-up period was $4.7 \pm 1.2$ years. A total of 731 participants underwent computed tomography (CT) twice: once at baseline and once at follow-up, until October 2013. Of these, 108 men were excluded due to missing information on PFV $(n=73)$ or a history of myocardial infarction/angina pectoris $(n=35)$. The remaining 623 participants were enrolled in the present study (Figure 1).

Anthropometric measurements (height, body weight [BW], and waist circumference [WC]) were obtained by trained nurses using a standard protocol at baseline and follow-up. Body mass index (BMI) was calculated as weight $(\mathrm{kg})$ divided by height squared $\left(\mathrm{m}^{2}\right)$. Blood pressure and heart rate were measured twice in a seated position after a 5-min rest using an automated sphygmomanometer (BP-8800; Omron Colin, Tokyo, Japan). The average of 2 measurements was used for analysis. Hypertension was defined as blood pressure $\geq 140 / 90 \mathrm{mmHg}$ or current use of antihypertensive drugs. Blood samples were obtained after 12 -h fast. Serum was separated by centrifugation $(1,000 \times \mathrm{g}$ for $15 \mathrm{~min}$ at $\left.4^{\circ} \mathrm{C}\right) \leq 90 \mathrm{~min}$ after sample collection. Samples were sent for routine laboratory testing, including lipid profiles and glucose. Total cholesterol and triglycerides were measured using enzymatic assay. High-density lipoprotein cholesterol (HDL-C) was determined using a direct method. Low-density lipoprotein cholesterol (LDL-C) was estimated using the Friedewald formula in participants with triglycerides $<400 \mathrm{mg} / \mathrm{dL}$. Lipid measurements were standardized according to the protocol set by the US Centers for Disease Control and Prevention/Cholesterol Reference Method Laboratory Network. Dyslipidemia was defined as LDL-C $\geq 140 \mathrm{mg} / \mathrm{dL}$, triglycerides $\geq 150 \mathrm{mg} / \mathrm{dL}$, HDL-C $<40 \mathrm{mg} / \mathrm{dL}$, or current use of lipid-lowering drugs. Glycated hemoglobin (HbAlc) was measured using the method suggested by the Japan Diabetes Society and was converted to the National Glycohemoglobin Standardization Program (NGSP) equivalent value. ${ }^{17}$ Diabetes mellitus was defined as $\mathrm{HbA1c}$ (NGSP) $\geq 6.5 \%$, fasting blood glucose $\geq 126 \mathrm{mg} / \mathrm{dL}$, or current use of anti-diabetic drugs. We obtained information on cigarette smoking, alcohol drinking, medical history, and disease history from selfadministered questionnaires at baseline and follow-up. Smoking status was categorized into 3 groups: "never", "ex", and "current" smoker. Participants who had never smoked were defined as "never smokers" and participants who smoked in the last 30 days were defined as "current smokers". Drinking status was categorized into 3 groups: "never", "ex", and "current" drinker. Participants who had never consumed alcohol were defined as "never drinkers" and participants who consumed alcohol habitually were defined as "current drinkers".

This study was conducted in accordance with the principles contained in the Declaration of Helsinki and approved by the Institutional Review Board of Shiga University of Medical Science (17-19, 17-83). Written informed consent was obtained from all participants.

Non-contrast CT was acquired using electron-beam CT with a C-150 scanner (Imatron, San Francisco, CA, USA) or using 16-channel multi-detector row CT (MDCT) at baseline and on MDCT at follow-up. Slice thickness was 3 $\mathrm{mm}$. PFV was measured using the same method as that of the Multi-Ethnic Study of Atherosclerosis (MESA) at Harbor University of California-Los Angeles Medical Center. 4,18 PFV was measured on axial images starting $15 \mathrm{~mm}$ above the superior extent of the left main coronary artery to $30 \mathrm{~mm}$ below that slice. Volume analysis software (GE Healthcare, Waukesha, WI, USA) was used to identify adipose tissue based on a corresponding threshold of $-190 \mathrm{HU}$ to $-30 \mathrm{HU}$ (mean, -120 HU).,18 According to a report from MESA, the intra-class correlation coefficients of intra-reader and inter-reader reliability for pericardial fat are 0.99 and 0.89 , respectively. ${ }^{4}$ We defined "pericardial fat" as adipose tissue inside and outside the pericardial sac. Change in PFV $\left(\mathrm{cm}^{3}\right)$ was calculated as PFV $\left(\mathrm{cm}^{3}\right)$ at follow-up minus PFV $\left(\mathrm{cm}^{3}\right)$ at baseline. 


\begin{tabular}{|c|c|}
\hline \multicolumn{2}{|l|}{ Variables } \\
\hline $\mathrm{n}$ & 623 \\
\hline Follow-up time (years) & $4.7 \pm 1.2$ \\
\hline Age (years) & $66.5 \pm 6.8$ \\
\hline Age range (years) & $40-79$ \\
\hline Body weight (kg) & $64.2 \pm 8.9$ \\
\hline BMI $\left(\mathrm{kg} / \mathrm{m}^{2}\right)$ & $23.4 \pm 2.9$ \\
\hline WC $(\mathrm{cm})$ & $85.0 \pm 8.0$ \\
\hline $\mathrm{SBP}(\mathrm{mmHg})$ & $137.7 \pm 18.3$ \\
\hline $\mathrm{DBP}(\mathrm{mmHg})$ & $80.4 \pm 10.7$ \\
\hline Heart rate (beats/min) & $64.5 \pm 10.1$ \\
\hline \multicolumn{2}{|l|}{ Smoking status } \\
\hline Never & 18.6 \\
\hline Ex & 52.3 \\
\hline Current & 29.1 \\
\hline \multicolumn{2}{|l|}{ Drinking status } \\
\hline Never & 16.1 \\
\hline Ex & 5.1 \\
\hline Current & 78.8 \\
\hline Total cholesterol (mg/dL) & $209.8 \pm 32.9$ \\
\hline Triglyceride (mg/dL) & $104.0(75.8-146.0)$ \\
\hline $\mathrm{HDL}-\mathrm{C}(\mathrm{mg} / \mathrm{dL})$ & $59.5 \pm 17.4$ \\
\hline LDL-C (mg/dL) & $125.6 \pm 30.7$ \\
\hline FBG (mg/dL) & $97.0(91.0-107.3)$ \\
\hline Hemoglobin A1c (\%) & $5.9(5.6-6.3)$ \\
\hline Hypertension & 57.9 \\
\hline Medication for hypertension & 32.6 \\
\hline Dyslipidemia & 55.1 \\
\hline Medication for dyslipidemia & 14.2 \\
\hline Diabetes & 19.4 \\
\hline Medication for diabetes & 10.1 \\
\hline $\operatorname{PFV}\left(\mathrm{cm}^{3}\right)$ & $64.1(47.2-90.0)$ \\
\hline
\end{tabular}

Data given as mean \pm SD, median (IQR) or $\%$. BMI, body mass index; DBP, diastolic blood pressure; FBG, fasting blood glucose; HDL-C, high-density lipoprotein-cholesterol; LDL-C, low-density lipoprotein-cholesterol; PFV, pericardial fat volume; SBP, systolic blood pressure; SESSA, Shiga Epidemiological Study of Subclinical Atherosclerosis; WC, waist circumference.

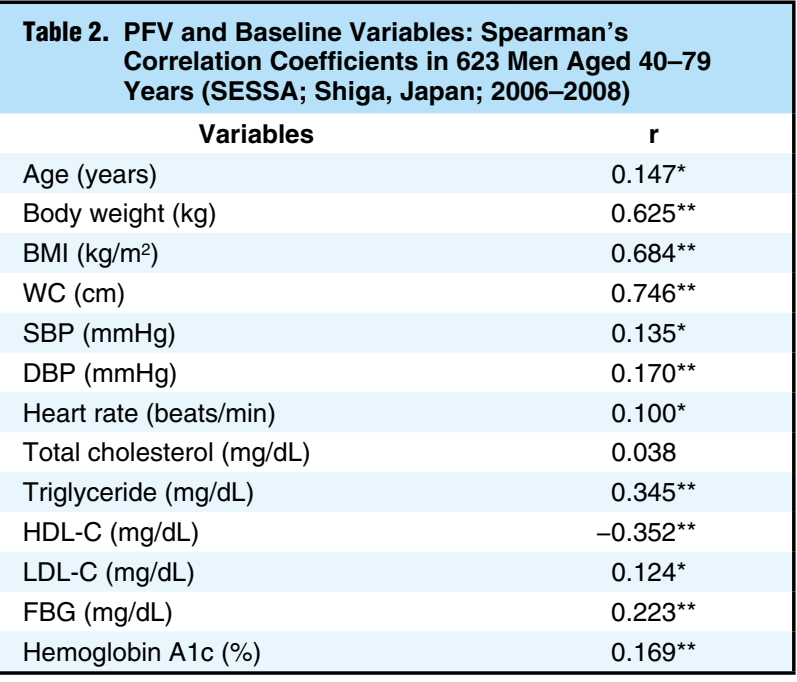

${ }^{*} \mathrm{P}<0.05 ;{ }^{* *} \mathrm{P}<0.01$. Abbreviations as in Table 1.

\section{Statistical Analysis}

Data are expressed as mean \pm SD for normally distributed continuous variables, or median (IQR) for non-normally distributed continuous variables. To compare paired data between 2 time-points, paired t-test was used for continuous variables and chi-squared test for categorical variables. Spearman's correlation analysis was used for continuous variables and analysis of variance for categorical variables to examine associations between classical cardiovascular risk factors and PFV at baseline and the change over time. Multivariable linear regression analysis was performed to examine the independent association between classical cardiovascular risk factors at baseline and PFV or its change. We selected confounders on multivariate analysis based on variables that were associated significantly with PFV on univariate analysis and from literature review. An ageadjusted model for each risk factor was estimated and multivariate regression analysis with backward selection was performed using a previous study for reference. ${ }^{19} \mathrm{We}$ included the follow-up time and CT type as covariates in all models. We performed a stratified analysis by age $(<65$, $\geq 65$ years). Statistical significance was defined as $\mathrm{P}<0.05$. All statistical analyses were conducted using SAS v9.4 (SAS Institute, Cary, NC, USA).

\section{Results}

Baseline participant characteristics are listed in Table 1. Mean age was $66.5 \pm 6.8$ years and mean BMI was $<25 \mathrm{~kg} / \mathrm{m}^{2}$. Mean BMI decreased slightly from $23.4 \pm 2.9 \mathrm{~kg} / \mathrm{m}^{2}$ to $23.2 \pm 2.9 \mathrm{~kg} / \mathrm{cm}^{2}$. Mean heart rate did not change during follow-up $(64.5 \pm 10.1$ beats/min at baseline and $64.3 \pm 10.6$ beats/ min at follow-up, $\mathrm{P}=0.684$ ). The percentage of ex-smokers was higher than that of current smokers. Approximately $80 \%$ of participants were current drinkers. Prevalence of hypertension, dyslipidemia, and diabetes was $57.9 \%, 55.1 \%$, and $19.4 \%$, respectively.

PFV was strongly and positively associated with obesity measurements (BW, BMI, and WC) at baseline (Table 2). PFV was also significantly and positively associated with age, heart rate, blood pressure as well as the level of triglycerides, LDL-C, fasting blood glucose, and HbAlc. HDL-C was inversely associated with PFV (Table 2). On multivariable linear regression analysis, age, heart rate, and current smoking were significantly and positively associated with PFV after adjustment for age and CT type (Table 3). In the backward selection model, BMI and dyslipidemia in addition to age and heart rate were significantly and positively associated with PFV. When adjusted for BW or WC instead of BMI, both BW and WC were significantly and positively associated with PFV (data not shown).

Over an average interval of 4.7 years, median PFV increased significantly from $64.1 \mathrm{~cm}^{3}$ (IQR, $47.2-90.0 \mathrm{~cm}^{3}$ ) to $73.6 \mathrm{~cm}^{3}$ (IQR, $53.3-98.1 \mathrm{~cm}^{3} ; \mathrm{P}<0.001$ ). $\mathrm{PFV}$ change is given in Figure 2. The change in PFV was positively associated with heart rate at baseline and inversely associated with age (Table 4). These associations were significant but were not so strong $(\mathrm{r}=0.100, \mathrm{P}=0.013$ and $\mathrm{r}=-0.106$ and $\mathrm{P}=0.008$, respectively). The change in PFV was not associated with baseline BW, BMI, or WC. The PFV change in current smokers was significantly higher than that in exsmokers and never smokers $\left(20.5 \pm 29.0 \mathrm{~cm}^{3}\right.$ vs. $11.4 \pm 23.4 \mathrm{~cm}^{3}$, $\mathrm{P}=0.001$; and vs. $8.1 \pm 20.7 \mathrm{~cm}^{3}, \mathrm{P}<0.001$, respectively). Drinking status was not associated with PFV change $(\mathrm{P}=0.569)$. On multivariable linear regression analysis, 


\begin{tabular}{|c|c|c|c|c|}
\hline & \multicolumn{2}{|c|}{ Adjusted for age, CT type } & \multicolumn{2}{|c|}{ Backward selection } \\
\hline & B & P-value & B & P-value \\
\hline Age (years) & 0.642 & 0.002 & 1.069 & $<0.001$ \\
\hline BMI $\left(\mathrm{kg} / \mathrm{m}^{2}\right)$ & -0.094 & 0.669 & 8.029 & $<0.001$ \\
\hline Heart rate (beats/min) & 0.145 & 0.020 & 0.479 & $<0.001$ \\
\hline Hypertension (Y/N) & 0.847 & 0.511 & & \\
\hline Dyslipidemia (Y/N) & 0.044 & 0.972 & 4.261 & 0.032 \\
\hline Diabetes mellitus $(\mathrm{Y} / \mathrm{N})$ & 2.069 & 0.174 & & \\
\hline \multicolumn{5}{|l|}{ Smoking status } \\
\hline Never & Ref. & & & \\
\hline Ex & -0.431 & 0.734 & & \\
\hline Current & 4.118 & 0.003 & & \\
\hline \multicolumn{5}{|l|}{ Drinking status } \\
\hline Never & Ref. & & & \\
\hline Ex & -3.031 & 0.249 & & \\
\hline Current & 0.107 & 0.944 & & \\
\hline
\end{tabular}

$\mathrm{R}^{2}$ for the backward selection model: 0.536 . CT, computed tomography. Other abbreviations as in Table 1 .

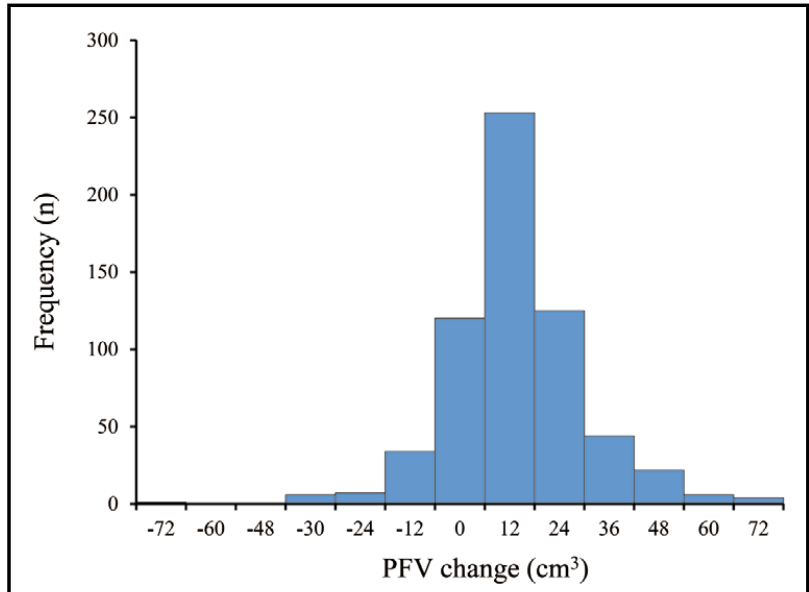

Figure 2. Distribution of change in pericardial fat volume (PFV).

change in PFV was significantly and independently associated with heart rate and current smoking in the model adjusted for age, CT type, and follow-up time (Table 5). The result was similar in the model with backward selection including all variables (Table 5). We divided the participants into 2 groups by age $(<65, \geq 65$ years) and found no interactions between these age groups and PFV change $(\mathrm{P}=0.790$ for interaction). When adjusted for $\mathrm{BW}$ or $\mathrm{WC}$ as other obesity measurements instead of BMI, heart rate and current smoking were also significantly and positively associated with PFV change $(B=0.133, P=0.037$ and $\mathrm{B}=6.841, \mathrm{P}=0.001$ for $\mathrm{BW} ; \mathrm{B}=0.0173, \mathrm{P}=0.007$ and $\mathrm{B}=4.433$, $\mathrm{P}=0.002$ for $\mathrm{WC}$, respectively). When the analysis was limited to those who did not change smoking status $(n=546)$, the results did not change (Table S1).

Finally, we considered change in BMI. On multivariable linear regression analysis with the backward selection model including all variables, change in PFV was significantly and independently associated with change in BMI

\begin{tabular}{|c|c|}
\hline $\begin{array}{l}\text { Correlation Coef } \\
\text { Years (SESSA; } \\
\text { Baseline and } 20\end{array}$ & $\begin{array}{l}\text { Spearman s } \\
08 \text { for } \\
\text { ) }\end{array}$ \\
\hline Variables & $\mathbf{r}$ \\
\hline Follow-up time (years) & $0.115^{\star *}$ \\
\hline Age (years) & $-0.106^{\star *}$ \\
\hline Body weight $(\mathrm{kg})$ & 0.040 \\
\hline BMI $\left(\mathrm{kg} / \mathrm{m}^{2}\right)$ & 0.024 \\
\hline WC $(\mathrm{cm})$ & 0.004 \\
\hline $\mathrm{SBP}(\mathrm{mmHg})$ & 0.031 \\
\hline $\mathrm{DBP}(\mathrm{mmHg})$ & 0.063 \\
\hline Heart rate (beats/min) & $0.100^{*}$ \\
\hline Total cholesterol (mg/dL) & 0.002 \\
\hline Triglyceride (mg/dL) & -0.040 \\
\hline HDL-C (mg/dL) & 0.064 \\
\hline LDL-C (mg/dL) & -0.023 \\
\hline FBG (mg/dL) & 0.009 \\
\hline Hemoglobin A1c (\%) & 0.013 \\
\hline PFV at baseline $\left(\mathrm{cm}^{3}\right)$ & 0.004 \\
\hline
\end{tabular}

${ }^{*} \mathrm{P}<0.05 ;{ }^{*} \mathrm{P}<0.01$. Abbreviations as in Table 1.

( $\mathrm{B}=8.79, \mathrm{P}<0.001)$ and current smoking $(\mathrm{B}=3.69, \mathrm{P}=0.001)$. The association between change in PFV and heart rate weakened slightly and showed marginal significance $(\mathrm{B}=0.09, \mathrm{P}=0.061)$.

\section{Discussion}

This is the first study to examine longitudinal changes in PFV in a community-based cohort. We found that PFV increased significantly over time. The change in PFV was significantly and independently associated with smoking status and heart rate.

On cross-sectional analysis, PFV significantly and positively correlated with heart rate, triglycerides, and obesity measurements (BW, BMI, and WC). PFV has been found to 


\begin{tabular}{|c|c|c|c|c|}
\hline & \multicolumn{2}{|c|}{$\begin{array}{l}\text { Adjusted for age, } \\
\text { CT type and follow-up time }\end{array}$} & \multicolumn{2}{|c|}{ Backward selection } \\
\hline & B & P-value & B & P-value \\
\hline Age (years) & -0.274 & 0.546 & & \\
\hline $\mathrm{BMI}\left(\mathrm{kg} / \mathrm{m}^{2}\right)$ & -0.101 & 0.647 & & \\
\hline Heart rate (beats/min) & 0.148 & 0.021 & 0.930 & 0.037 \\
\hline Hypertension (Y/N) & 0.838 & 0.519 & & \\
\hline Dyslipidemia (Y/N) & -0.011 & 0.993 & & \\
\hline Diabetes mellitus $(\mathrm{Y} / \mathrm{N})$ & 2.084 & 0.178 & & \\
\hline \multicolumn{5}{|l|}{ Smoking } \\
\hline Never & Ref. & & & \\
\hline Ex & -0.385 & 0.080 & 3.064 & 0.070 \\
\hline Current & 4.109 & 0.004 & 6.841 & 0.001 \\
\hline \multicolumn{5}{|l|}{ Drinking } \\
\hline Never & Ref. & & & \\
\hline Ex & -3.087 & 0.243 & & \\
\hline Current & 0.120 & 0.938 & & \\
\hline Follow-up time (years) & -0.498 & 0.854 & & \\
\hline PFV at baseline $\left(\mathrm{cm}^{3}\right)$ & -0.013 & 0.501 & & \\
\hline
\end{tabular}

$\mathrm{R}^{2}$ for the backward selection model: 0.05 . Abbreviations as in Tables 1,3 .

be positively associated with obesity measurements. $\mathbf{3 , 5 , 1 0 , 1 1 , 1 5 , 2 0}$ Studies in Japanese populations with a lower prevalence of obesity have also reported a positive association between PFV and obesity measurements. ${ }^{\mathbf{1 2}}$ Although CAD patients were examined specifically in those studies, the present results are consistent with these.

Higher heart rate was associated significantly with higher PFV at baseline. We did not find other studies that examined the association between heart rate and PFV. It has been reported that PFV is related to heart rate recovery, which was used as an index of cardiac autonomic nervous dysfunction. ${ }^{21,22}$ Autonomic nervous dysfunction has been reported to be caused by fat accumulation in visceral adipose tissue in an animal model. ${ }^{23}$ PFV shares a common embryonic origin with abdominal visceral fat, ${ }^{24}$ and has a positive correlation with abdominal obesity. A higher heart rate has also been reported to be a predictor of $\mathrm{CVD}^{25}$ and all-cause mortality. ${ }^{26}$ The positive relationship between heart rate and PFV might be suggestive of cardiac autonomic dysfunction in the present study. We did not detect a change in heart rate during follow-up because heart rate was recorded with high accuracy, and was measured after a 5-min rest using an automated sphygmomanometer in the present study.

The mechanisms through which smoking increases PFV are complex and incompletely understood. Cigarette smokers tend to have lower $\mathrm{BMI}^{27}$ in the short term because nicotine can reduce appetite and increase energy expenditure. ${ }^{28}$ Paradoxically, smokers have also been reported to gain $\mathrm{BW}$ in a longitudinal study ${ }^{29}$ and to have increased abdominal adiposity. ${ }^{30,31}$ Nicotine is a sympathomimetic agent and promotes the release of catecholamine. ${ }^{28}$ Nicotine is also a strong activator of the hypothalamicpituitary-adrenal axis, ${ }^{32}$ and increases energy expenditure by increasing the metabolic rate, leading to insulin resistance, which affects fat distribution. ${ }^{28}$ Another biologic explanation is that smoking may reduce the testosterone concentration, ${ }^{33}$ which is a determinant of changes in body composition. ${ }^{34}$ In addition, smokers tend to have unfavorable lifestyle habits, such as higher alcohol consumption and lower physical activity. ${ }^{35,36}$ Therefore, smokers tend to have a greater volume of visceral adipose tissue. We have already reported that smoking status is cross-sectionally associated with a greater degree of abdominal obesity. ${ }^{37}$ We assume that the same mechanism could explain the association between PFV and smoking. In addition, a significant association between smoking status and resting heart rate was noted by Linneberg et al. ${ }^{38}$ We suggest that smoking and increasing resting heart rate might contribute (at least in part) to the risk of CVD.

Some studies in which PFV was evaluated on ultrasound ${ }^{39,40}$ and only one study in which PFV was evaluated on $\mathrm{MDCT}^{15}$ reported a similar result to that of the present study: PFV change is associated with BMI change. In morbidly obese patients, bariatric surgery reduces BMI significantly and cardiac ectopic fat volume also decreases significantly after bariatric surgery. ${ }^{41} \mathrm{~A}$ change in BW or BMI influences a change in PFV because visceral adipose tissue is readily influenced by changes in BW or BMI rather than subcutaneous adipose tissue. ${ }^{42}$ The clinical importance of the change in PFV (rather than baseline PFV itself) is poorly understood. Additional studies are needed to clarify which parameter would be more important clinically.

\section{Study Limitations}

This study had 4 main limitations. First, the study cohort consisted only of Japanese men, which limits the applicability of the results to women and to other ethnicities. In particular, there is a difference in body fat distribution according to sex. ${ }^{43}$ Second, smoking parameters were based on selfreport, which could lead to potential misclassification and could underestimate the true association. Third, we could not examine the longitudinal influence of change in PFV according to change in smoking status because of the small size of the cohort and the short duration of observation. And finally, we could not examine the longitudinal influ- 
ence of change in PFV according to change in heart rate because of the short duration of observation and small change in heart rate. Heart rate was recorded with high accuracy: it was measured after a 5-min rest using an automated sphygmomanometer unattended by medical staff. We examined the association between different variables at baseline and change in PFV. Next, we will attempt to elucidate the longitudinal effect of change in variables on PFV change.

\section{Conclusions}

PFV increased significantly over time in a cohort of Japanese men. The change in PFV was significantly and independently associated with smoking status and heart rate, suggesting that quitting smoking might reduce PFV. Further studies that examine the influence of increased PFV on cardiovascular disease (CVD) outcome are needed to contribute to CVD prevention.

\section{Acknowledgments}

Shiga Epidemiological Study of Subclinical Atherosclerosis (SESSA) Research Group

Chairperson: Hirotsugu Ueshima (Center for Epidemiologic Research in Asia, Department of Public Health, Shiga University of Medical Science, Otsu, Japan).

Katsuyuki Miura (Department of Public Health, Shiga University of Medical Science, Otsu, Japan); Minoru Horie, Yasutaka Nakano, Takashi Yamamoto (Department of Cardiovascular and Respiratory Medicine, Shiga University of Medical Science, Otsu, Japan); Emiko Ogawa (Health Administration Center, Shiga University of Medical Science, Otsu, Japan); Hiroshi Maegawa, Itsuko Miyazawa (Division of Endocrinology and Metabolism, Department of Medicine, Shiga University of Medical Science, Otsu, Japan); Kiyoshi Murata (Department of Radiology, Shiga University of Medical Science, Otsu, Japan); Kenichi Mitsunami (Shiga University of Medical Science, Otsu, Japan); Kazuhiko Nozaki (Department of Neurosurgery, Shiga University of Medical Science, Otsu, Japan); Akihiko Shiino (Biomedical MR Science Center, Shiga University of Medical Science, Otsu, Japan); Isao Araki (Kusatsu Public Health Center, Kusatsu, Japan); Teruhiko Tsuru (Department of Urology, Shiga University of Medical Science, Otsu, Japan); Ikuo Toyama (Unit for Neuropathology and Diagnostics, Molecular Neuroscience Research Center, Shiga University of Medical Science, Otsu, Japan); Hisakazu Ogita, Souichi Kurita (Division of Medical Biochemistry, Department of Biochemistry and Molecular Biology, Shiga University of Medical Science, Otsu, Japan); Toshinaga Maeda (Central Research Laboratory, Shiga University of Medical Science, Otsu, Japan); Naomi Miyamatsu (Department of Clinical Nursing Science Lecture, Shiga University of Medical Science, Otsu, Japan); Toru Kita (Kobe City Medical Center General Hospital, Kobe, Japan); Takeshi Kimura (Department of Cardiovascular Medicine, Kyoto University, Kyoto, Japan); Yoshihiko Nishio (Department of Diabetes, Metabolism, and Endocrinology, Kagoshima University, Kagoshima, Japan); Yasuyuki Nakamura (Department of Living and Welfare, and Cardiovascular Epidemiology, Kyoto Women's University, Kyoto, Japan); Tomonori Okamura (Department of Preventive Medicine and Public Health, School of Medicine, Keio University, Tokyo, Japan); Akira Sekikawa, Emma JM Barinas-Mitchell (Department of Epidemiology, Graduate School of Public Health, University of Pittsburgh, Pittsburgh, PA, USA); Daniel Edmundowicz (Department of Medicine, Section of Cardiology, School of Medicine, Temple University, Philadelphia, PA, USA); Takayoshi Ohkubo (Department of Hygiene and Public Health, Teikyo University School of Medicine, Tokyo, Japan); Atsushi Hozawa (Preventive Medicine, Epidemiology Section, Tohoku University, Tohoku Medical Megabank Organization, Sendai, Japan); Nagako Okuda (Department of Health and Nutrition, University of Human Arts and Sciences, Saitama, Japan); Aya Kadota (Department of Public Health, Shiga University of Medical Science, Otsu, Japan); Aya Higashiyama (Research and Development Initiative Center, National Cerebral and Cardiovascular Center, Suita, Japan); Shinya Nagasawa (Department of Epidemiology and Public Health, Kanazawa Medical University, Kanazawa, Japan); Yoshikuni Kita (Tsuruga Nursing University, Tsuruga, Japan); Akira Fujiyoshi, Naoyuki Takashima, Takashi Kadowaki, Sayaka Kadowaki
(Department of Public Health, Shiga University of Medical Science, Otsu, Japan); Yoshitaka Murakami (Department of Medical Statistics, Faculty of Medicine, Toho University, Tokyo, Japan); Robert D Abbott, Seiko Ohno, Maryam Zaid (Center for Epidemiologic Research in Asia, Shiga University of Medical Science, Otsu, Japan); Takashi Hisamatsu (Department of Environmental Medicine and Public Health Faculty of Medicine, Shimane University, Izumo, Japan); Naoko Miyagawa, Sayuki Torii, Yoshino Saito, Masahiro Yamazoe, Sentaro Suzuki, Takahiro Ito (Department of Public Health, Shiga University of Medical Science, Otsu, Japan).

\section{Disclosures}

The authors declare no conflicts of interest.

\section{Funding Sources}

This work was supported by Grants-in-Aid for Scientific Research from the Ministry of Education, Culture, Sports, Science, and Technology, Japan [(A) 13307016, (A) 17209023, (A) 21249043, (A) 23249036, (A) 25253046, (B) 23390174, and (C) 23590791]; and GlaxoSmithKline. The funding source had no role in study design; in the collection, analysis, or interpretation of data; in writing the report; or in the decision to submit the manuscript for publication.

\section{References}

1. Britton KA, Fox CS. Ectopic fat depots and cardiovascular disease. Circulation 2011; 124: e837-e841.

2. Sacks HS, Fain JN. Human epicardial adipose tissue: A review. Am Heart $J$ 2007; 153: 907-917.

3. Bettencourt N, Toschke AM, Leite D, Rocha J, Carvalho M, Sampaio F, et al. Epicardial adipose tissue is an independent predictor of coronary atherosclerotic burden. Int J Cardiol 2012; 158: $26-32$.

4. Ding J, Hsu FC, Harris TB, Liu Y, Kritchevsky SB, Szklo M, et al. The association of pericardial fat with incident coronary heart disease: The Multi-Ethnic Study of Atherosclerosis (MESA). Am J Clin Nutr 2009; 90: 499-504.

5. Ding J, Kritchevsky SB, Harris TB, Burke GL, Detrano RC, Szklo M, et al. The association of pericardial fat with calcified coronary plaque. Obesity (Silver Spring) 2008; 16: 1914-1919.

6. Alexopoulos N, McLean DS, Janik M, Arepalli CD, Stillman AE, Raggi P. Epicardial adipose tissue and coronary artery plaque characteristics. Atherosclerosis 2010; 210: 150-154.

7. Sarin S, Wenger C, Marwaha A, Qureshi A, Go BD, Woomert $\mathrm{CA}$, et al. Clinical significance of epicardial fat measured using cardiac multislice computed tomography. Am J Cardiol 2008; 102: $767-771$

8. Mahabadi AA, Massaro JM, Rosito GA, Levy D, Murabito JM, Wolf PA, et al. Association of pericardial fat, intrathoracic fat, and visceral abdominal fat with cardiovascular disease burden: The Framingham Heart Study. Eur Heart J 2009; 30: 850-856.

9. Mahabadi AA, Berg MH, Lehmann N, Kalsch H, Bauer M, Kara K, et al. Association of epicardial fat with cardiovascular risk factors and incident myocardial infarction in the general population: The Heinz Nixdorf Recall Study. J Am Coll Cardiol 2013; 61: 1388-1395.

10. Rosito GA, Massaro JM, Hoffmann U, Ruberg FL, Mahabadi AA, Vasan RS, et al. Pericardial fat, visceral abdominal fat, cardiovascular disease risk factors, and vascular calcification in a community-based sample: The Framingham Heart Study. Circulation 2008; 117: 605-613.

11. Okura K, Maeno K, Okura S, Takemori H, Toya D, Tanaka N, et al. Pericardial fat volume is an independent risk factor for the severity of coronary artery disease in patients with preserved ejection fraction. $J$ Cardiol 2015; 65: 37-41.

12. Taguchi R, Takasu J, Itani Y, Yamamoto R, Yokoyama K, Watanabe $\mathrm{S}$, et al. Pericardial fat accumulation in men as a risk factor for coronary artery disease. Atherosclerosis 2001; 157: 203 209.

13. Hirata Y, Kurobe H, Akaike M, Chikugo F, Hori T, Bando Y, et al. Enhanced inflammation in epicardial fat in patients with coronary artery disease. Int Heart J 2011; 52: 139-142.

14. Nakanishi R, Rajani R, Cheng VY, Gransar H, Nakazato R, Shmilovich $\mathrm{H}$, et al. Increase in epicardial fat volume is associated with greater coronary artery calcification progression in subjects at intermediate risk by coronary calcium score: A serial study using non-contrast cardiac CT. Atherosclerosis 2011; 218: $363-368$. 
15. Nakazato R, Rajani R, Cheng VY, Shmilovich H, Nakanishi R, Otaki $\mathrm{Y}$, et al. Weight change modulates epicardial fat burden: A 4-year serial study with non-contrast computed tomography. Atherosclerosis 2012; 220: 139-144.

16. Ueshima H, Kadowaki T, Hisamatsu T, Fujiyoshi A, Miura K, Ohkubo T, et al. Lipoprotein-associated phospholipase A2 is related to risk of subclinical atherosclerosis but is not supported by Mendelian randomization analysis in a general Japanese population. Atherosclerosis 2016; 246: $141-147$.

17. Kashiwagi A, Kasuga M, Araki E, Oka Y, Hanafusa T, Ito H, et al. International clinical harmonization of glycated hemoglobin in Japan: From Japan Diabetes Society to National Glycohemoglobin Standardization Program values. J Diabetes Investig 2012; 3: 39-40.

18. Ahmadi N, Nabavi V, Yang E, Hajsadeghi F, Lakis M, Flores $\mathrm{F}$, et al. Increased epicardial, pericardial, and subcutaneous adipose tissue is associated with the presence and severity of coronary artery calcium. Acad Radiol 2010; 17: 1518-1524.

19. Kronmal RA, McClelland RL, Detrano R, Shea S, Lima JA, Cushman M, et al. Risk factors for the progression of coronary artery calcification in asymptomatic subjects: Results from the Multi-Ethnic Study of Atherosclerosis (MESA). Circulation 2007; 115: $2722-2730$

20. Mahabadi AA, Lehmann N, Kalsch H, Robens T, Bauer M, Dykun I, et al. Association of epicardial adipose tissue with progression of coronary artery calcification is more pronounced in the early phase of atherosclerosis: Results from the Heinz Nixdorf recall study. JACC Cardiovasc Imaging 2014; 7: 909916.

21. Kim DJ, Cho KI, Cho EA, Lee JW, Park HJ, Kim SM, et al. Association among epicardial fat, heart rate recovery and circadian blood pressure variability in patients with hypertension. Clin Hypertens 2015; 21: 24.

22. Sengul C, Duman D. The association of epicardial fat thickness with blunted heart rate recovery in patients with metabolic syndrome. Tohoku J Exp Med 2011; 224: 257-262.

23. Katagiri H, Yamada T, Oka Y. Adiposity and cardiovascular disorders: Disturbance of the regulatory system consisting of humoral and neuronal signals. Circ Res 2007; 101: 27-39.

24. Ho E, Shimada Y. Formation of the epicardium studied with the scanning electron microscope. Dev Biol 1978; 66: 579-585.

25. Okamura T, Hayakawa T, Kadowaki T, Kita Y, Okayama A, Elliott P, et al. Resting heart rate and cause-specific death in a 16.5-year cohort study of the Japanese general population. Am Heart $J$ 2004; 147: 1024-1032.

26. Diaz A, Bourassa MG, Guertin MC, Tardif JC. Long-term prognostic value of resting heart rate in patients with suspected or proven coronary artery disease. Eur Heart $J$ 2005; 26: $967-$ 974.

27. Albanes D, Jones DY, Micozzi MS, Mattson ME. Associations between smoking and body weight in the US population: Analysis of NHANES II. Am J Public Health 1987; 77: 439-444.

28. Audrain-McGovern J, Benowitz NL. Cigarette smoking, nicotine, and body weight. Clin Pharmacol Ther 2011; 90: 164-168.

29. Stice E, Marti CN, Rohde P, Shaw H. Young woman smokers gain significantly more weight over 2-year follow-up than nonsmokers: How Virginia doesn't slim. Appetite 2015; 85: 155-159.

30. Canoy D, Wareham N, Luben R, Welch A, Bingham S, Day N, et al. Cigarette smoking and fat distribution in 21,828 British men and women: A population-based study. Obes Res 2005; 13:
$1466-1475$.

31. Shimokata H, Muller DC, Andres R. Studies in the distribution of body fat: III. Effects of cigarette smoking. JAMA 1989; 261: $1169-1173$

32. Rohleder N, Kirschbaum C. The hypothalamic-pituitary-adrenal (HPA) axis in habitual smokers. Int J Psychophysiol 2006; 59: 236-243.

33. Meikle AW, Liu XH, Taylor GN, Stringham JD. Nicotine and cotinine effects on 3 alpha hydroxysteroid dehydrogenase in canine prostate. Life Sci 1988; 43: 1845-1850.

34. Vermeulen A, Goemaere S, Kaufman JM. Testosterone, body composition and aging. $J$ Endocrinol Invest 1999; 22: 110-116.

35. Tuovinen EL, Saarni SE, Mannisto S, Borodulin K, Patja K, Kinnunen TH, et al. Smoking status and abdominal obesity among normal- and overweight/obese adults: Population-based FINRISK study. Prev Med Rep 2016; 4: 324-330.

36. Chiolero A, Faeh D, Paccaud F, Cornuz J. Consequences of smoking for body weight, body fat distribution, and insulin resistance. Am J Clin Nutr 2008; 87: 801 -809.

37. Fujiyoshi A, Miura K, Kadowaki S, Azuma K, Tanaka S, Hisamatsu T, et al. Lifetime cigarette smoking is associated with abdominal obesity in a community-based sample of Japanese men: The Shiga Epidemiological Study of Subclinical Atherosclerosis (SESSA). Prev Med Rep 2016; 4: 225-232.

38. Linneberg A, Jacobsen RK, Skaaby T, Taylor AE, Fluharty ME, Jeppesen JL, et al. Effect of smoking on blood pressure and resting heart rate: A mendelian randomization meta-analysis in the CARTA Consortium. Circ Cardiovasc Genet 2015; 8: 832-841.

39. Kim MK, Tanaka K, Kim MJ, Matuso T, Endo T, Tomita T, et al. Comparison of epicardial, abdominal and regional fat compartments in response to weight loss. Nutr Metab Cardiovasc Dis 2009; 19: 760-766.

40. Iacobellis G, Singh N, Wharton S, Sharma AM. Substantial changes in epicardial fat thickness after weight loss in severely obese subjects. Obesity (Silver Spring) 2008; 16: 1693-1697.

41. Gaborit B, Jacquier A, Kober F, Abdesselam I, Cuisset T, Boullu-Ciocca S, et al. Effects of bariatric surgery on cardiac ectopic fat: Lesser decrease in epicardial fat compared to visceral fat loss and no change in myocardial triglyceride content. $J \mathrm{Am}$ Coll Cardiol 2012; 60: 1381-1389.

42. Fujioka S, Matsuzawa Y, Tokunaga K, Kawamoto T, Kobatake $\mathrm{T}$, Keno Y, et al. Improvement of glucose and lipid metabolism associated with selective reduction of intra-abdominal visceral fat in premenopausal women with visceral fat obesity. Int $J$ Obes 1991; 15: 853-859.

43. Enzi G, Gasparo M, Biondetti PR, Fiore D, Semisa M, Zurlo F Subcutaneous and visceral fat distribution according to sex, age, and overweight, evaluated by computed tomography. Am J Clin Nutr 1986; 44: 739-746.

\section{Supplementary Files}

\section{Supplementary File 1}

Table S1. Multivariate indicators of change in PFV in 546 men aged 40-79 years who did not change smoking status (SESSA; Shiga, Japan; 2006-2008 for baseline and 2010-2014 for follow-up)

Please find supplementary file(s);

http://dx.doi.org/10.1253/circj.CJ-18-0153 